\title{
FNAC: A Simple \& Cost-Effective Diagnostic Tool for Benign \& Malignant Pathologies Associated with Cervical Lymphadenopathy
}

${ }^{1}$ Sohail Anwar, ${ }^{2}$ Amna Rehman, ${ }^{3}$ Asifa Karamat, ${ }^{4}$ Huma Batool, ${ }^{2}$ Ali Afzal

${ }^{I}$ Department of Pulmonology, University of Lahore Teaching Hospital, Lahore

${ }^{2}$ Department of Histopathology, Gulab Devi Hospital, Lahore

${ }^{3}$ Department of Pulmonology, Gulab Devi Hospital, Lahore

${ }^{4}$ Department of Pulmonology, Lahore General Hospital, Lahore

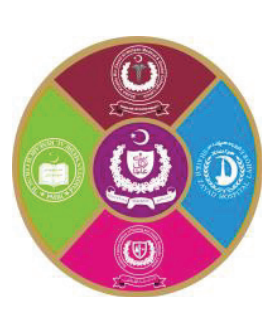

\begin{abstract}
Introduction: Cervical lymphadenopathy is very common as the presenting complaint in our outpatient departments. Its etiology may either be benign or malignant. Fine needle aspiration cytology (FNAC) is a comparatively cheap, easy to perform minimally invasive test. It has become the go to test to determine the cause of lymphadenopathy

Aims \& Objectives: To determine whether FNAC is a cost-effective diagnostic tool in evaluation of various benign and malignant Pathologies associated with cervical lymphadenopathy.

Place and duration of study: It is a retrospective study conducted at Gulab Devi Hospital from April 2019 to April 2021.

Material \& Methods: The cyto-morphologic features seen in the aspirates were critically analyzed and correlated with their etiology. SPSS version 24.0 was analyzed for data analysis. A p-value of $<0.05$ was considered significant.

Results: Among the 100 patients 56 were females and 44 were males with a female to male ratio of $1.3: 1$. The age range of the patients was from 3 to 75 years. $37 \%$ were reactive lymphadenitis, $32 \%$ were tuberculosis, $12 \%$ were suppurative, $11 \%$ were lymphoproliferative disorders, $8 \%$ cases were metastatic neoplasm.

Conclusion: FNAC is a reliable and cost effective to diagnose the etiologies of cervical lymphadenopathy.
\end{abstract}

Key words: Fine needle aspiration cytology, Cervical Lymphadenopathy

\section{INTRODUCTION}

$\mathrm{T}_{\mathrm{h}}$ increase in size of lymph node is called lymphadenopathy. Increase in the size of cervical lymph nodes of more than $1 \mathrm{~cm}$ is called cervical lymphadenopathy. ${ }^{1}$ It is arguably the common presentations of patients in the OPD. Cervical lymphnode enlargement has multiple etiologies like infections, malignancies, auto immune pathology etc. ${ }^{2}$ Treatment modalities of all the causative agents for cervical lymphadenopathy are different so it is vital to diagnose the etiology for lymph node enlargement.

There are various options for diagnosing the cause of enlargement of lymph nodes. Fine Needle Aspiration Cytology (FNAC) is one of such option. FNAC is a procedure used to procure fluid, cells and tissues by means of a disposable syringe with a thin needle inserted for diagnosing masses. ${ }^{3}$ Greig and Gray in 1904 used it first to diagnose trypanosomiasis. In 1921 Guthrie used fine-needle aspiration on lymph nodes for diagnosis on lymph node sand was further used as a diagnostic tool in 1930 by Martin and Ellis. ${ }^{4}$ It is a safe, quick, reliable and comparatively cheap procedure used as first line for diagnosing lymph node enlargement and plays a vital part in differentiating between benign and malignant lesions especially of cervical lymph nodes. FNAC can be conducted in Outpatient Department with very little special equipment involved and causes no disfigurement. ${ }^{5}$ The gold standard for the diagnosis of cervical lymph node enlargement is Excision Biopsy however, the requirement of operation theatre, anesthesia, strict asepsis and with the complication of scar formation, is not generally preferred. ${ }^{6}$

This article evaluates the contribution of FNAC in the diagnosis of cervical lymph node enlargement, shedding light on cervical lymph node enlargement cytopathological patterns at Gulab Devi Hospital, Lahore, Pakistan.

\section{MATERIAL AND METHODS}

A retrospective study at Gulab Devi Hospital was conducted from April 2019 to April 2021, after 
acquiring the Institutional Review Board approval (IRB) letter No: AAMC/DME/IRB/EA2218. We included cases of cervical lymphadenopathy referred from various inpatient and outpatient clinical departments irrespective of gender and age. Patients with lymph node enlargement other than cervical were excluded from this study. Patients were assessed by history, physical examination, and local examination of the cervical lymph node. Informed consent was taken after explaining the entire procedure to the patient discussing the benefits and adverse effects. A 22-gauge needle bound to a $10-\mathrm{mLsyringe}$ was used to aspirate Lymph node without local anesthesia, under aseptic conditions. Smears were made from every patient. May-Grunwald-Giemsa (MGG) stain was used for air dried smear staining and Papanicolaou (PAP) stain was used for alcohol fixed smears staining. Ziehl-Neelsen staining was carried out in smears of all tuberculosis suspects. Hematoxylin and eosin $(\mathrm{H}$ \& E) stains were used for histopathology slides. After reviewing slides classification of the results were made as neoplastic and non-neoplastic lesion.

\section{Statistical analysis:}

Statistical Package for Social Sciences (SPSS, version 24) for Windows was used for analysis.

\section{RESULTS}

In our study out of 100 patients 56 were female and 44 were male (Fig-1). Most of the FNACs done in Gulab Devi Hospital were of patients aged between $10-20$ years with female predominance while least number of patients presented for FNAC were in their 60 s with equal gender distribution (Fig-2). The frequency of distribution of the cases shows $81 \%$ had benign diagnosis and 19\% came back malignant (Fig-3). In malignant cases we included lymphoproliferative and metastatic (Fig-10A) while rest were included in benign. In benign causes reactive (Fig-10C) was the commonest followed by tuberculous (Fig-10B) and in malignancy lymphoproliferative disorder was predominant (Fig4). In female patients, TB was the commonest diagnosis $35.7 \%$ followed by reactive $32.1 \%$ with malignant diagnosis in $16.1 \%$ (Fig-5). In male patients, reactive lymph nodes were found in majority $43.2 \%$ of patients followed by $27.3 \%$ patients with TB. Malignancy was found in $22.7 \%$ of males (Fig-6). In 1-to-20-year age group tuberculosis was the predominant diagnosis with female dominance in benign while lymphoproliferative disorders were common also with female dominance (Fig-7). In 20 to 40 age group reactive with male dominance was the commonest benign diagnosis while metastasis was in more female patients than males. No patients of lymphoproliferative disorders were seen (Fig-8). In age group of 40 onwards reactive with male dominance was the commonest benign diagnosis while lymphoproliferative disorders dominated with all male patients in this age group (Fig-9).

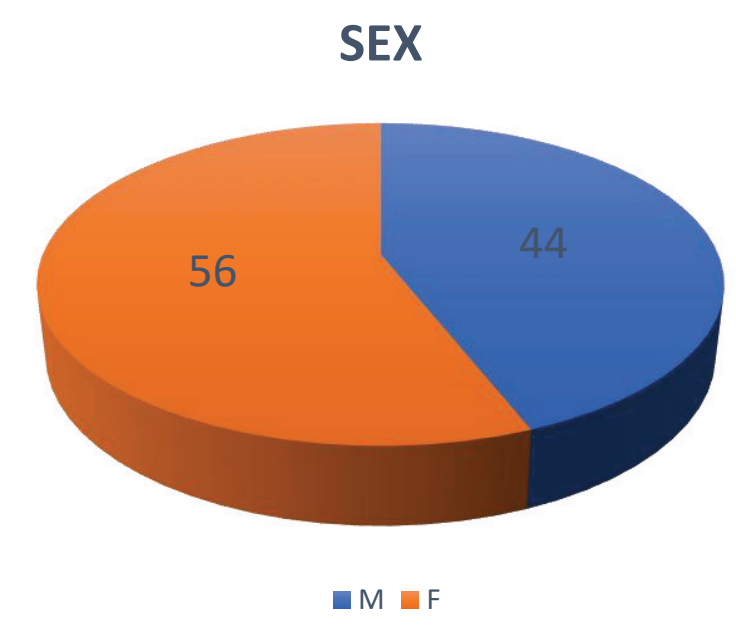

Fig-1: Distribution according to Sex

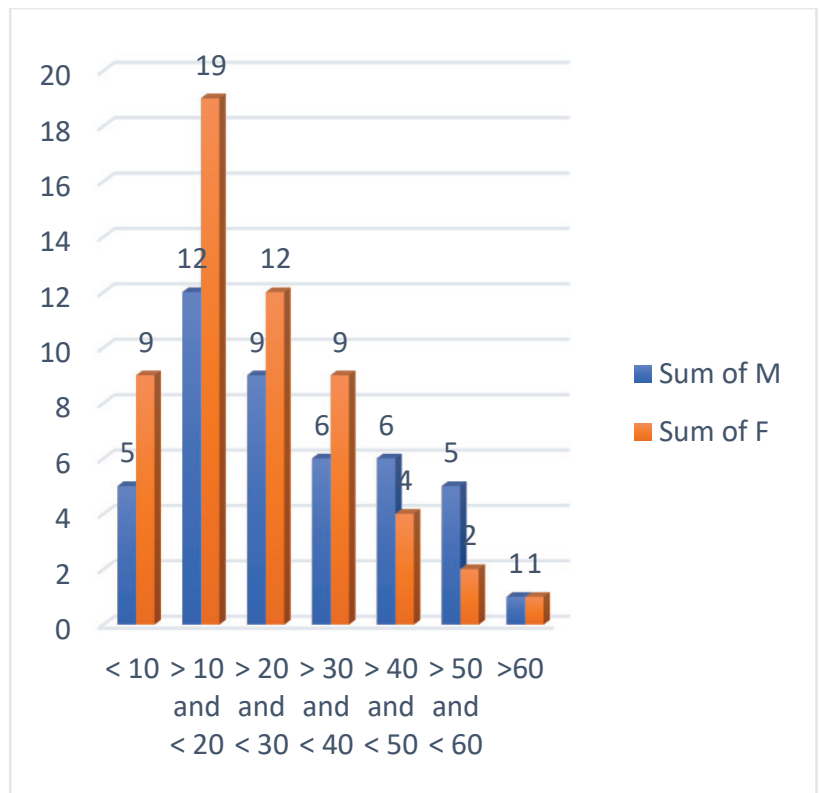

Fig-2: Distribution according to Age

\begin{tabular}{|c|c|}
\hline FNAC DIAGNOSIS & Number of Patients $\%$ \\
\hline Benign & $81 \%$ \\
\hline Malignant & $19 \%$ \\
\hline
\end{tabular}

Fig-3: Distribution According to Severity 


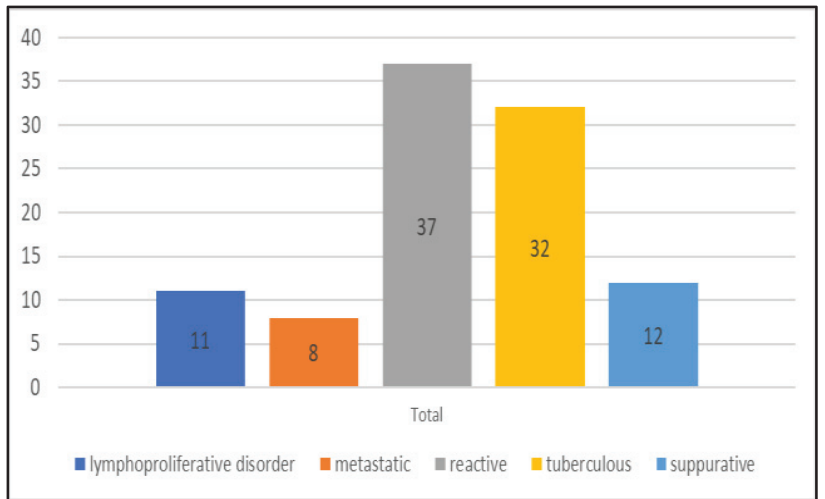

Fig-4: Distribution according to diagnosis

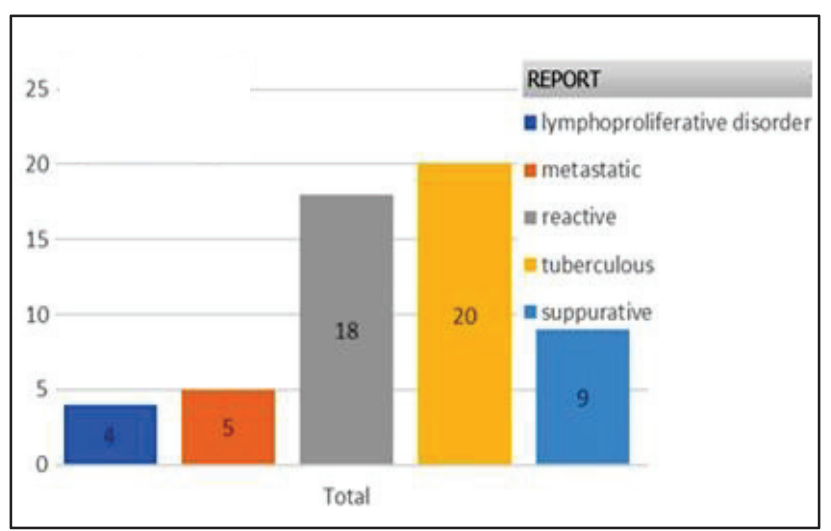

Fig-5: Distribution of cases in females

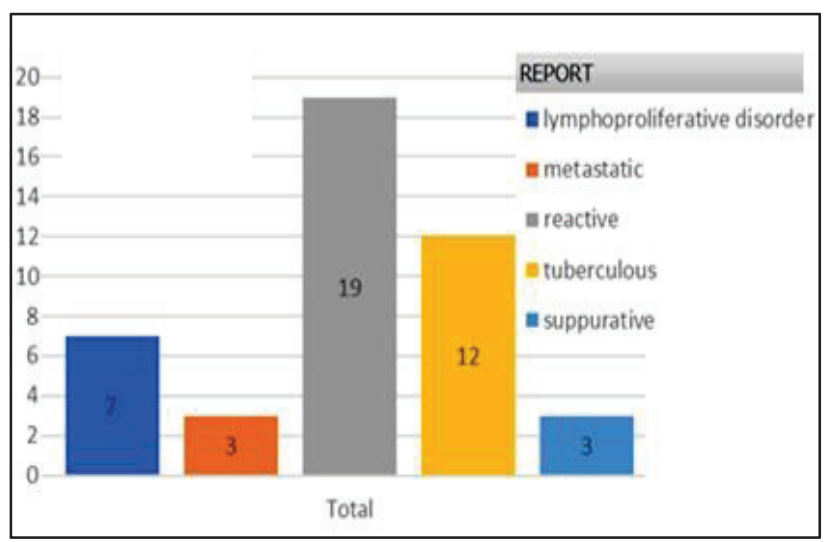

Fig-6: Distribution of cases in Males

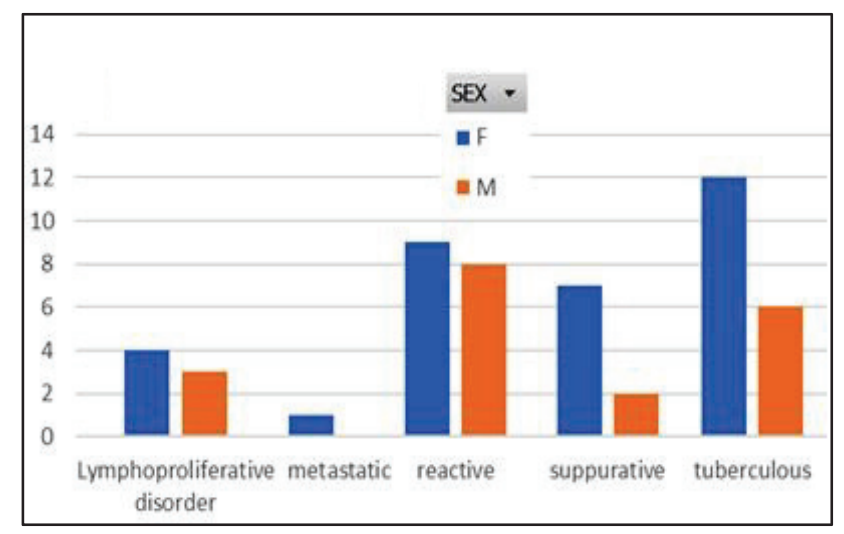

Fig-7: Pattern of Distribution in $0-20$ age group

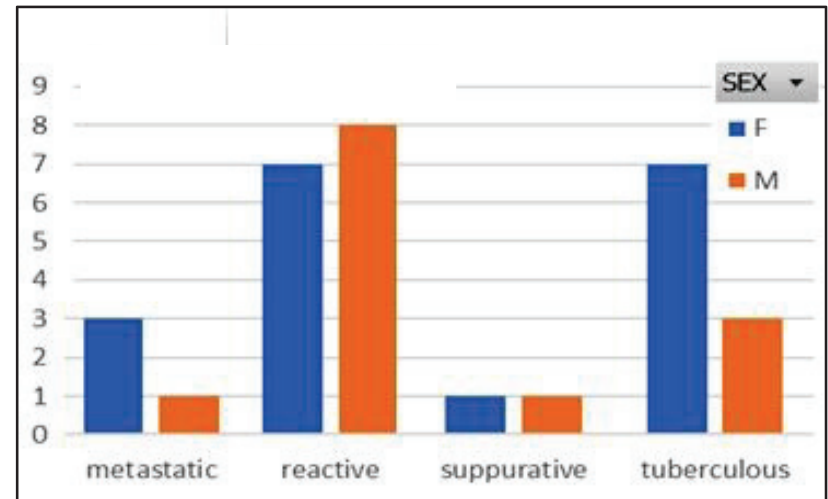

Fig-8: Pattern of distribution in 21- 40 age group

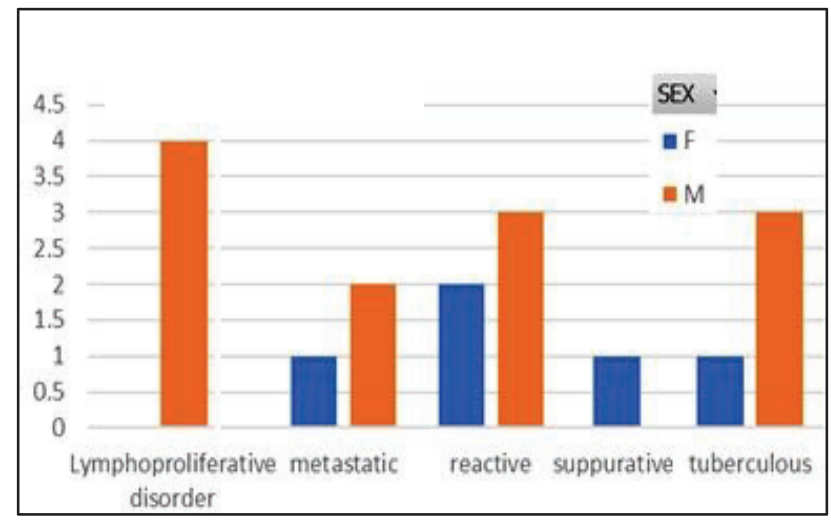

Fig-9: Pattern of distribution in more than 40 age group

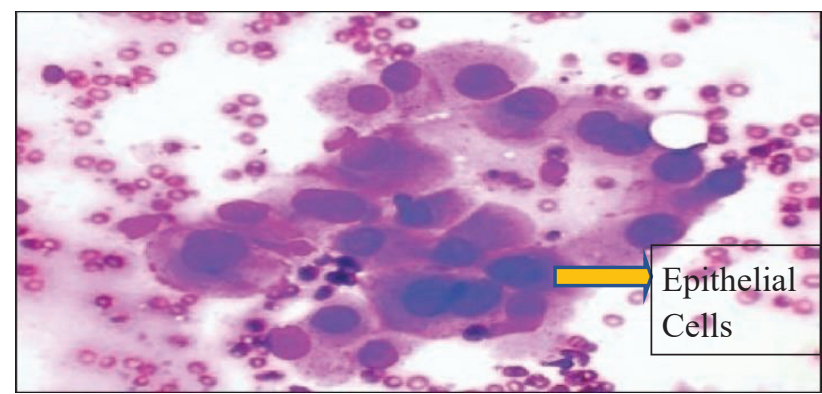

Fig-10A: Metastatic

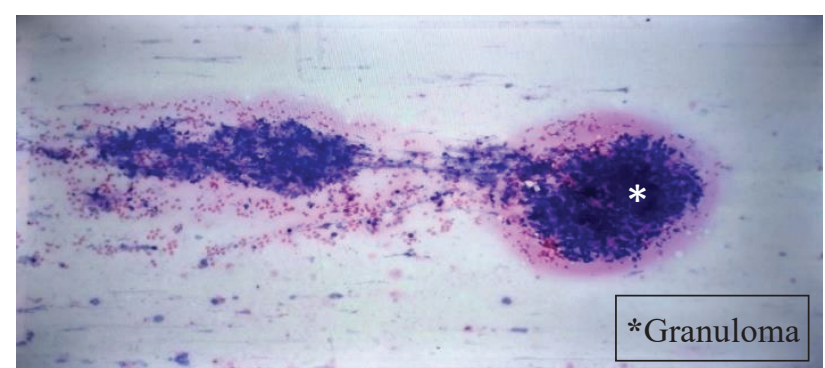

Fig-10B: Tuberculous

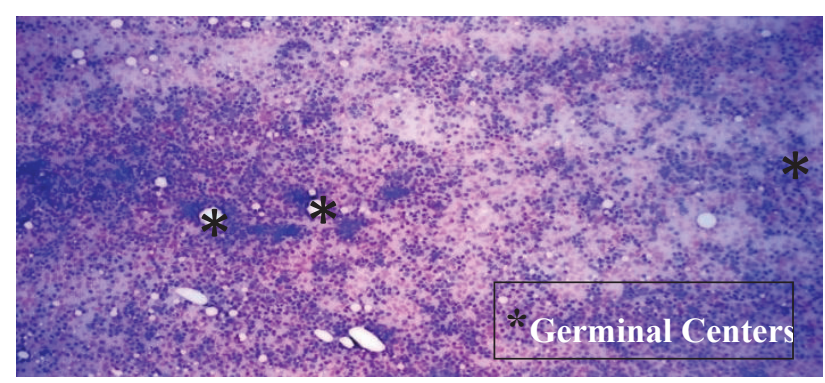

Fig-10C: Reactive 


\section{DISCUSSION}

When cervical lymph nodes increase in size larger than $1 \mathrm{~cm}$ it is referred to as cervical lymph node enlargement. Multiple diseases can cause enlarging of lymph nodes, the spectrum of diseases varies from benign to malignant. Enlarged lymph nodes are easily palpable and approachable for fine needle aspiration cytology. This procedure's significance in the diagnosis of cervical lymph adenopathy is noteworthy especially in developing countries like Pakistan.

FNAC is a comparatively cheap procedure, easily performed with very few complications. In some instances, FNAC may be the only option available for diagnosis as surgical biopsy could not be done for very reasons. FNAC diagnosis has been shown to correlate with histopathological diagnosis after biopsy.

There is wide age range of cervical lymphadenopathy. In the present study the age range was 3-75 years. In this study there was female predominance with a ratio of $1.3: 1$. Which is comparable to Badge et al. ${ }^{7}$ However, some studies show a slight male dominance. ${ }^{8}$ The most frequently observed age group for cervical lymphadenopathy in our study is 11 to 20 years which is similar to those of Sejwal et al. ${ }^{9}$ In our study $81 \%$ were benign and $19 \%$ were malignant which is similar to Kadam et al. ${ }^{10}$ Reactive lymphadenitis was deemed to be the commonest cause of cervical lymphadenopathy in our study with its percentage among total cases being $37 \%$. Similar results were quoted by DeDeePya $\mathrm{M}$ et al. ${ }^{11}$ Tuberculous lymphadenitis in our study came out to be $32 \%$ which correlates with study of Urmila et al. ${ }^{12}$ Lymphoproliferative disorders contribute to $11 \%$ of the total cases which is near to study by Houcine et al. ${ }^{13}$ Metastatic carcinoma contribute to $8 \%$ of the total cases which is similar to Shrivastava et al. ${ }^{14}$

Regarding age groups, it was observed that tuberculous lymphadenitis was commonly seen in 1 to 20 age group $40 \%$, as tuberculosis has a high incidence in a developing country like Pakistan ${ }^{15}$ while reactive lymphadenitis was common $41.7 \%$ in 21 to 40 age group similar to Shameema et al. ${ }^{16}$ In our study malignant diagnosis mainly, lymphoproliferative disorders were common in 1-20 compromising $17.8 \%$ of the total. The incidence of lymphoproliferative disorders is high in developing countries $^{17}$. It again peaked in age group of 40 and above with $36.8 \%$ of the total cases which is similar to Shakera et al. ${ }^{18}$

FNAC hence proved to be an accurate and costeffective procedure in evaluation of clinically palpable lumps, especially in lymph nodes. The variable factors which may be responsible for low yield can be performer experience, smear spreading technique and crushing artifacts.

Based on the findings in our study we found that FNAC is an extremely useful tool in the evaluation of palpable cervical lymph node. In most of the cases excludes the need of an excision biopsy and assisting in initiating appropriate treatment. The ancillary techniques such as immunohistochemistry can be applied whenever sufficient material is available for cell blocks and this would further augment in establishing the diagnosis.

\section{CONCLUSION}

FNAC is a relatively cheap, easy to perform and dependable procedure to investigate the cause of cervical lymph node enlargement. Tuberculosis is the commonest diagnosis in a developing country like Pakistan. For malignancies FNAC can propose a preliminary diagnosis which can be further confirmed and classified by biopsy, histopathology and immunostaining.

\section{REFERENCES}

1. Patar Mukul, Borsaikia Kusum et al. A clinicopathological evaluation of cervical lymphadenopathy in children (0-14 Years) by fine needle aspiration cytology and histopathological examination - A hospital-based study. National Journal of Otorhinolaryngology and Head \& Neck Surgery, Vol. 2 (11) No. 2, August 2014

2. Bhasker N. Review of Head and Neck Masses in the Indian Population Based on Prevalence and Etiology with an Emphasis on Primary Diagnostic Modalities. Cureus. $2021 \mathrm{Jul}$; 13(7).

3. Pathy PC, Hota SK, Dash S, Samantaray S, Panda S, Rout N. Analysis of FNAC in diagnosis of lymphadenopathy-a retrospective study from a regional cancer centre, Cuttack, Odisha. International Journal of Research in Medical Sciences. 2017 Dec; 5(12):5287.

4. Singh A, Bhambani P, Nema S. Diagnostic accuracy of FNAC in the diagnosis for the causes of lymphadenopathy: a hospital-based analysis. Int $\mathrm{J}$ Res Med Sci. 2013; 1(3):271-77.

5. Advani SK, Aqil S, Dahar A. Role of fine needle aspiration cytology (FNAC) in neck masses/cervical lymphadenopathy. Pakistan Journal of Chest Medicine. 2015 Jun 13; 14(3).

6. Ryu YJ, Cha W, Jeong WJ, Choi SI, Ahn SH. Diagnostic role of core needle biopsy in cervical lymphadenopathy. Head \& neck. 2015 Feb; 37(2):229-33.

7. Badge SA, Ovhal AG, Azad K, Meshram AT. Study of fine-needle aspiration cytology of lymph node in 
rural area of Bastar District, Chhattisgarh. Medical Journal of Dr. DY Patil University. 2017 Mar 1; 10(2):143.

8. Malhotra AS, Lahori M, Nigam A, Khajuria A. Profile of lymphadenopathy: An institutional based cytomorphological study. Int J App Basic Med Res. 2017; 7:100-3

9. Sejwal P, Jaiswal M, Pandey S. Utility of Fine Needle Aspiration Cytology as a Low-cost Tool to Diagnose Cervical Lymphadenopathy. Iranian journal of pathology. 2018; 13(3):340.

10. Kadam SA, Miskin AT, Dombale VD. Role of FNAC in study of cytomorphological patterns in cervical lymph node. Medica. 2020 Jul; 9(2):88.

11. DeDeePya M, RAMASWAMY A, KUMARGURU B, KUMAR MU. A Comparative Study of Cytomorphological Patterns of Lymph Node Aspirates in Paediatric and Adult Populations. Journal of Clinical \& Diagnostic Research. 2020 Oct $1 ; 14(10)$.

12. Urmila K, Haobam S, Thiyam U. FNAC as a simple tool for the diagnosis of superficial lymphadenopathy--a study in an institute in the north-eastern states of India. Journal of Evolution of Medical and Dental Sciences. 2018 Mar 12; 7(11):1328-33.

13. Houcine Y, Romdhane E, Blel A, Ksentini M, Aloui R, Lahiani R, Znaidi N, Salah MB, Rammeh S. Evaluation of fine needle aspiration cytology in the diagnosis of cervical lymph node lymphomas. Journal of Cranio-Maxillofacial Surgery. 2018 Jul 1; 46(7):1117-20.

14. Shrivastava JP, Shrivastava A, Singh S, Gaur R. Role of FNAC in the evaluation of cervical lymph nodes: A hospital-based study. J Evolution Med and Dent Sci. 2015 Jul 9; 4:9643-8.

15. Laghari M, Sulaiman SA, Khan AH, Memon N. Epidemiology of tuberculosis and treatment outcomes among children in Pakistan: a 5 year retrospective study. PeerJ. 2018 Jul 27; 6:e5253.

16. Shameema S. Cytological spectrum of disease in Lymph node swellings among patients attending a tertiary care teaching hospital with special emphasis on tuberculous lymphadenitis. Saudi J Pathol Microbiol. 2017; 2(5):185-91.

17. Namayandeh SM, Khazaei Z, Najafi ML, Goodarzi E, Moslem A. GLOBAL Leukemia in children 0-14 statistics 2018, incidence and mortality and human development index (HDI): GLOBOCAN sources and methods. Asian Pacific journal of cancer prevention: APJCP. 2020 May; 21(5):1487.

18. Shakera NB, Vaishali A, Sharma R, Kunal S D, MitalChokshi. Analysis of FNAC of cervical lymph nodes-Experience over a two years period. International Journal of Medical Science and Public Health. 2014; 3(5):607-9.

\section{The Authors:}

Dr. Sohail Anwar

Assistant Professor,

Department of Pulmonology,

University of Lahore Teaching Hospital, Lahore.

Dr. Amna Rehman

Post Graduate Trainee,

Department of Histopathology,

Gulab Devi Hospital, Lahore.

Dr. Asifa Karamat

Assistant Professor,

Department of Pulmonology,

Gulab Devi Hospital, Lahore.

Dr. Huma Batool

Assistant Professor,

Department of Pulmonology,

Lahore General Hospital, Lahore.

Dr. Ali Afzal

Post Graduate Trainee, Department of Histopathology, Gulab Devi Hospital, Lahore.

\section{Corresponding Author:}

Dr. Sohail Anwar

Assistant Professor,

Department of Pulmonology,

University of Lahore Teaching Hospital, Lahore.

E-mail: sohail.anwar@ucm.uol.edu.pk 